\title{
PEREMPUAN KERINCI SEBAGAI IDE DALAM PENCIPTAAN KARYA SENI LUKIS
}

\author{
Nia Daniati ${ }^{1 *}$, Andar Indra Sastra ${ }^{2 *}$, Dharsono $^{3 *}$ \\ Minat Penciptaan Seni Kriya Program Pascasarjana \\ Institut Seni Indonesia Padangpanjang \\ Jl. Bahder Johan, Guguak Malintang, Padangpanjang, Kota Padangpanjang, 27126. \\ Sumatera Barat. Indonesia. \\ Email: 30niadaniati@gmail.com
}

\begin{abstract}
Abstrak
Perempuan di daerah Kerinci sangat diistimewakan, seperti menarik garis keturunan dari pihak ibu (perempuan) yang disebut dengan sistem matrilineal. Selain menarik garis keturunan dari pihak ibu (perempuan) sistem pewarisan juga datangnya dari kaum perempuan, seperti sko (pusaka) yang berbentuk gelar, tetapi dipakai oleh mamak (saudara laki-laki ibu) dan orang sumendo (suami ibu); dan harta pusaka tinggi; seperti rumah dan sawah dikendalikan oleh perempuan. Perempuan Kerinci selalu menerapkan etika beradat kemanapun pergi, sehingga mereka dihormati dan disegani di dalam masyarakat. Etika beradat perempuan Kerinci yakni "sesuai dengan Icopake." Icopakeperempuan Kerinci sifatnya lunak atau lemah lembut, seperti malu pada laki-laki, takut pada janji, mulut manih kecindam murah (ketika berbicara lemah lembut tutur katanya dan sopan santun), pandai memilihara diri, rajin mengurus rumah tangga, , dan menurut kata junjungan (suami). Metode yang dipakai dalam penciptaan karya ini observasi, dokumentasi, dan eksperimen. Karya ini menggambarkan tentang kekaguman pengkarya terhadap perempuan Kerinci yang diwujudkan kedalam karya seni lukis dengan menghadirkan berbagai kegiatan yang dilakukan oleh perempuan Kerinci dalam kehidupan sehari-hari. Perwujudan karya menggunakan konsep reinterpretasi yang menggambarkan kembali aktivitas perempuan Kerinci dalam berbagai aspek mulai dari kesawah sampai pada aktivitasnya dalam adat yang diwujudkan ke dalam karya seni lukis dengan gaya dekoratif.
\end{abstract}

Kata Kunci: Perempuan Kerinci, kekaguman dan seni lukis

\begin{abstract}
Kulouk is one Women in Kerinci regency are very special, such as drawing a bloodline from mother (female) called the matrilineal system. In addition to drawing a line frommother (female) inheritance system also came from women, such as sko (heirloom) in the form of a title, but was used by mamak (mother's brother) and sumendo (mother's husband); and high inheritance, like houses and rice fields controlled by women. Kerinci women always apply ethical ethics wherever they go, so they were respected in society. Kerinci's civilized ethics are "in accordance with the Icopake." Icopake female Kerinci is soft or gentle, such as being ashamed of men, fear of promises, low-priced mouth when she speaks softly and politely), good at choosing herself, diligently taking care of the household, and according to the word lord (husband). The method used in the creation of this work is observation, documentation, and experimentation. This work illustrates the admiration of the artists for Kerinci women who embodied the work of painting by presenting various activities carried out by Kerinci women in their daily lives. The embodiment of the work uses the concept of reinterpretation which reillustrates the activities of Kerinci women in various aspects ranging from the crater to the activities in adat which are embodied in painting with decorative style..
\end{abstract}

Keywords: Kerinci's women, admiration and painting

\section{PENDAHULUAN}

Perempuan di daerah Kerinci sangat diistimewakan, seperti menarik garis keturunan dari pihak ibu (perempuan) yang disebut dengan sistem matrilineal. Sistem matrilineal di Sumatera terdapat pada enam suku bangsa yakni suku Enggano di Bengkulu, suku Petangan di Riau, suku Sakai di Riau, suku Ocu di Riau, suku Minangkabau di Sumatera Barat dan suku Kerinci di Jambi.
Sistem matrilineal di Kerinci selain menarik garis keturunan dari pihak ibu (perempuan), sko (pusaka) yang berbentuk gelar juga datangnya dari kaum perempuan tetapi dipakai oleh mamak (saudara laki-laki ibu) dan orang sumendo (suami ibu); dan harta pusaka tinggi; seperti rumah dan sawah dikendalikan oleh perempuan. Terutama perempuan yang memakai kuluk (penutup kepala sekaligus mahkota kebesaran bagi perempuan) 


\section{Gorga Jurnal Seni Rupa \\ Volume 07 Nomor 02 \\ p-ISSN: 2301-5942 | e-ISSN: 2580-2380}

yang merupakan seorang raja (penguasa atau pemimpin) berkuasa untuk mengendalikan harta pusaka dan warisan (Risnal. 1996:32).

Selain itu kuluk juga merupakan identitas daerah Kerinci seperti yang terdapat pada salah satu lirik lagu Kerinci yang berjudul "Sakti Alam Kerinci" ciptaan Atmajar Idris yang berbunyi, ngaleh alah jangki tando uhang kinci, pakai alah kuluk di bucincin pulo artinya memikul jangki tanda orang Kerinci, memakai kuluk yang ada cincinnya. Ini juga bermakna bahwa masyarakat Kerinci menganut faham matrilineal (menurut garis keturunan ibu) karna yang memakai kuluk adalah kaum perempuan. Jadi tidak salah kalau kuluk dijadikan sebagai ciri khas orang Kerinci yang menjunjung tinggi seorang perempuan.

Berdasarkan penjelasan di atas sebagai generasi muda sekaligus perempuan (gadis) Kerinci, merasa kagum terhadap perempuan Kerinci yang mempunyai sifat lemah lembut sesuai dengan icopake. Dalam hal itu muncullah keinginan untuk melahirkan sebuah karya terinspirasi dari perempuan Kerinci yang akan diwujudkan ke dalam karya seni lukis. Seni lukis merupakan seni sebagai suatu ungkapan pengalaman estetik seorang seniman yang dituangkan ke dalam bidang dua dimensi dengan menggunakan medium rupa yaitu garis, warna, bidang, tekstur dan lain-lain. Unsur-unsur tersebut bertujuan untuk menyampaikan perasaan ataupun pengalaman batin seorang seniman. Mencermati apa yang diungkapkan oleh seorang tokoh teori seni bernama Soedarsono SP (Mike Susanto, 2002: 101) yang menyatakan bahwa "Seni adalah karya yang berkomunikasi untuk menyampaikan pengalaman batin seorang seniman, yang disajikan secara indah sehingga merangsang manusia lain untuk merasakan hal yang sama”.

Ketertarikan pengkarya terhadap perempuan Kerinci untuk mengekspresikan ide tentang perempuan Kerinci dalam berbagai aktivitas. Penciptaan karya ini tidak hanya untuk menyampaikan pesan kepada generasi muda tentang peran seorang perempuan di Kerinci yang patut dijadikan tauladan, tetapi juga untuk mengevaluasi diri sendiri agar menerapkan sifatsifat sesuai dengan icopake dan menjadi perempuan ideal Kerinci, seperti yang tergambar pada kuluk yang akan diwujudkan melalui karya seni.
Penciptaan karya ini menggunakan bahan kanvas, cat akrilik, dengan teknik mixed media yang memakai manik-manik, perca kain dan teknik impasto (mengecat dengan cat yang tebal). Pemilihan teknik ini selain pengkarya lebih akrab dan supaya karakteristik perempuan yang ingin disampaikan dapat dipahami oleh penikmat.

\section{Tujuan Penciptaan dan Manfaat Penciptaan}

1).Menciptakan karya seni lukis dengan ide perempuan Kerinci.

2).Dapat menjadi referensi bagi generasi muda Kerinci tentang aktivitas Perempuan Kerinci.

3).Secara akademik menjadi referensi bagi seniman lainnya untuk berbagi apresiasi tentang karya lukis reinterpretasi yang berangkat dari ide tentang Perempuan Kerinci.

\section{KAJIAN TEORI}

\section{Teori Estetika}

Suatu karya seni yang diciptakan bukanlah manifestasi sembarangan mencipta asal jadi. Suatu karya seni dilahirkan karena dorongan yang menyeluruh, kuat dan banyak segi. Untuk menciptakan karya yang baik tidak asal-asalan yaitu memakai 3 unsur seperti yang dinyatakan oleh Manroe Bardley dalam Dharsono Sony Kartika, 2007: 63, bahwa "ada 3 unsur yang paling utama dalam membuat karya seni yang baik dan benar dari benda-benda estetis pada umumnya yaitu (1) Unity (kesatuan) dari unsur-unsur seni rupa (garis, bidang, warna, tekstur, ruang, dan lain-lain) hal ini dilakukan pengkarya untuk menambah kesan suasana kekaguman yang dirasakan. (2)Complexity (kerumitan/ kompleksitas) dari unsur-unsur estetis tidak terlihat mudah malainkan kaya akan isi dan makna, nilai kerumitan karya terlihat pada perbedaan antara karya satu dengan karya lain yang akan diciptakan. (3) Itensity (kesungguhan) untuk menciptakan karya terdapat suatu kulitas yang menonjol seperti tekstur, warna, bentuk, dan lainya. Hal tersebut yang akan menunjukkan bahwa karya seni yang diciptakan secara sungguh-sungguh, dan akan terlihat dari kesempurnaan penggarapan karya yang akan diciptakan.

\section{Teori Ekspresi}

Seni tidak bisa lepas dari ekspresi, yang selalu menghadirkan ide-ide kreatif dalam bekarya. Ekspresi adalah sesuatu yang dikeluarkan seperti perasaan dan pikiran dalam bentuk yang baru. Bentuk-bentuk baru merupakan proses kreatifitas pengkarya dalam merespon objek dan fenomena-fenomena yang terjadi dalam masyarakat. Proses kreatif adalah luasnya kegiatan mental dan fisik mulai dari dorongan awal hingga sentuhan terakhir, yaitu antara kita bermaksud 


\section{Gorga Jurnal Seni Rupa \\ Volume 07 Nomor 02 \\ p-ISSN: 2301-5942 | e-ISSN: 2580-2380}

mencapai sesuatu hingga karya seni itu selesai (Agus sachari dalam Dharsono, 2007:73).

\section{Reinterpretasi}

Karya sangit sebagai bentuk reproduksi yang mengacu pada bentuk pelestarian seni tradisi, dengan mencoba memberikan alternatif karya dengan teknik reproduksi inovasi garap, seperti yang diungkapkan oleh Dharsono. Penciptaan karya ini memakai konsep reinterpretasi yang merupakan pemanfaatan cerita sebagai sumber gagasan dan pemanfaatan idiom tradisi secara terstruktur mengacu pada teknik seni modern (Dharsono 105: 2016).

Seni Tradisi merupakan seni yang tak terlepaskan dari semua pola dan ikatan tradisional yang monomental. Menciptakan karya seni dengan pemanfatan idiom tradisi, secara struktur yang mengacu pada teknik modern. Penciptaan karya ini menjadi spirit awal lahir karya seni lukis dengan menghadirkan benda-benda tradisi, seperti jangki, baju kurung dan kuluk dengan gaya dekoratif. Karya tersebut, dengan konsep reinterpretasi mampu melestarikan kembali benda tradisi dengan teknik modern, disaat sekarang. Di bawah ini merupakan bentuk karya yang telah diciptakan.

\section{Dekoratif}

Penciptaan karya ini memakai gaya dekoratif yang merupakan daya (unsur) menghias yang tinggi atau dominan.

\section{METODE PENCIPTAAN}

Metode merupakan tatacara sistematis dalam melakukan pekerjaan agar tercapai sesuai dengan perencanaan. Setiap individu mempunyai metode yang berbeda dengan individu lainya sesuai dengan keperluan dan caranya masing-masing.

\section{Riset Emik}

\section{1).Observasi}

Observasi merupakan tahap awal dalam melahirkan sebuah karya seni yakni melakukan pengamatan terhadap aktivitas perempuan Kerinci dalam kehidupan sehari-hari untuk mendapatkan informasi yang dibutuhkan dalam penciptaan karya berupa foto, buku dan wawancara.

\section{2). Wawancara}

Wawancara dilakukan untuk mendapatkan informasi yang terkait dengan perempuan Kerinci dengan melakukan wawacara dengan narasumber yang ahli dalam bidangnya, seperti bapak Sadikin yang merupakan Ninik Mamak di Kerinci.
Sadikin (75), dalam wawancaranya beliau menyatakan; perempuan Kerinci zaman dahulu adalah perempuan yang taat terhadap perintah orangtua maupun perintah suami dan memiliki sifat mulut manih kecimdam murah, budi baik baso ktuju artinya pandai dalam berbicara, lembut tutur katanya dan berprilaku baik (wawancara, 2018 Perempuan seperti ini merupakan contoh perempuan yang disenangi oleh orang banyak).

\section{3).Dokumentasi}

Dokumentasi merupakan kegiatan dalam pengumpulan data berupa foto tentang aktivitas perempuan Kerinci terutama dalam kegiatan pertanian, seperti kesawah, keladang, memetik teh dan sebagainya. Objek ini digunakan sebagai inspirasi dalam melahirkan karya nantinya.

\section{4).Proses Imajinasi (Kreasi)}

Proses imajinasi atau melakukan perenungan merupakan kegiatan untuk menemukan gambaran dalam mencari simbol yang akan dipakai sebagai bahasa ekspresi, kemudian akan digunakan sebagai motif pokok (utama), motif pendukung, dan motif isian. Tahap ini pengkarya menemukan ciri khas visualisasi perempuan yang akan dihadirkan pada karya nantinya dengan bentuk visualisasi perempuan sudah distorsi dan stilisasi. Salah satunya visualisasi yang distorsi, yakni membuat visualisualisasi perempuan lebih tinggi dan langsing dengan ukuran mata lebih besar dari ukuran normal dengan bentuk bulu mata segi tiga berbanjar. Penggayaan terhadap bentuk pakaian dan motif pakaian yang dipakai pada perempuan Kerinci.

\section{HASIL DAN PEMBAHASAN}

\section{Hasil Karya 1}

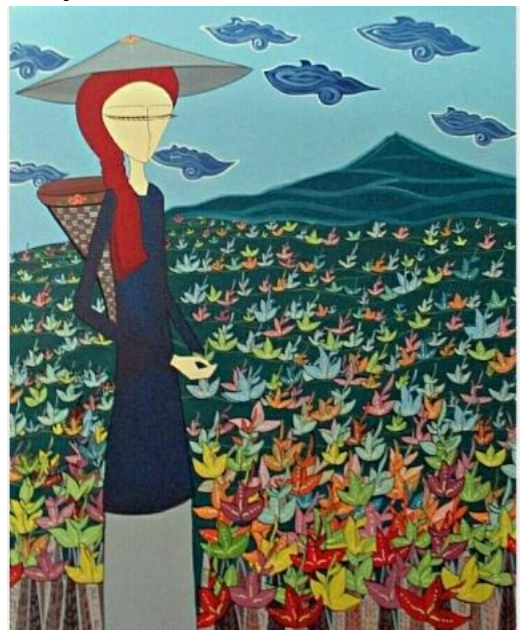

Gambar 1.

Judul: Menyambut Pagi Ukuran: 150 x 120 cm 


\section{Gorga Jurnal Seni Rupa \\ Volume 07 Nomor 02 \\ p-ISSN: 2301-5942 | e-ISSN: 2580-2380}

\section{1).Deskripsi Karya}

Karya yang berjudul "Menyambut Pagi" di buat pada tahun 2018 berukuran 150 x $120 \mathrm{~cm}$ dengan teknik plakat pada kanvas. Karya di atas terdapat visualisasi perempuan yang memakai, tudung lindak (caping) yang berwarna abu-abu tua, tengkuluk yang berwarna merah, baju kurung berwarna biru tua dengan bawah dipakai trap (kain sarung) yang berwarna abu-abu, jangki berwarna coklat dengan warna anyaman abuabu tua dan abu-abu muda. Visualisasi perempuan dibuat sedang memejamkan mata dengan bulu mata yang tebal, bibir bewarna merah dan alis yang bewarna hitam. Pada belakang visualisasi perempuan terdapat kebun teh dengan daun teh yang berwarna kuning, merah, hijau, toska, ungu, pink, dan oranye. Pada bagian atas background terdapat visualisasi langit berwarba biru muda yang diselingi oleh visualisasi awan yang berwarna biru tua dengan kontur warna putih.

\section{2).Analisis}

Bentuk karya ini berlandaskan konsep reinterpretasi yang mana memanfaatkan cerita sebagai ide garap dan memanfaatkan jangki, tengkuluk dan baju kurung sebagai ideom tradisional yang banyak digunakan oleh masyarakat dulu.

\section{3). Interpretasi}

Karya ini menginterpretasikan tentang keanggunan seorang gadih kinci (perempuan Kerinci) dalam memetik teh dengan memakai benda tradisi sebagai alat untuk mengangkut teh yang bermakna agar bendabenda tradisi seperti jangki dan baju kurung tetap dipakai oleh masyarakat Kerinci saat sekarang ini agar budaya kita tidak punah termakan zaman.

\section{Hasil Karya 2}

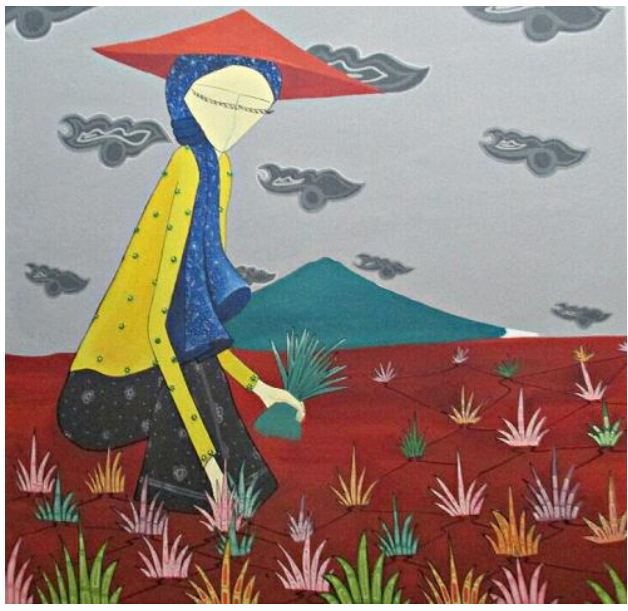

Gambar 2.

Judul: Dimunanam Ukuran: 120 x 120 cm Bahan: Mixed Media (Foto: Nia Daniati)

\section{1). Deskripsi Karya}

Karya yang berjudul "Dimunanam" di buat pada tahun 2018 berukuran 150 x $120 \mathrm{~cm}$ menggunakan teknik mixed media. Karya di atas terdapat visualisasi perempuan yang memakai, tudung lindak (caping) yang berwarna coklat, tengkuluk yang berwarna biru tua, baju kurung berwarna kuning dengan motif bunga yang berwarba hijau dan bagian bawah dipakai trap (kain sarung) yang berwarna dengan motif bungabunga.. Pada bawah karya tedapat tanah yang berwarna coklat yang tumbuhi dengan padi yang berwarna hijau, toska, ungu, pink, dan oranye. Pada bagian atas background terdapat visualisasi langit berwarba abu-abu muda yang diselingi oleh visualisasi awan yang berwarna abu-abu tua.

\section{2).Analisis}

Bentuk karya ini berlandaskan konsep reinterpretasi yang mana memanfaatkan cerita sebagai ide garap tentang perempuan Kerinci dalam bertani di sawah dengan memakai benda-benda tradisi, seperti tengkuluk dan baju kurung sebagai ideom tradisional yang banyak digunakan oleh masyarakat dulu dalam kehidupan sehari-hari.

\section{3).Interpretasi}

Karya ini menginterpretasikan tentang keanggunan seorang perempuan Kerinci dalam bertani dalam hal ini mananam padi di sawah. Terlihat visualisasi perempuan dengan tangan yang lemah lembut menanam padi demi satu padi di tanamkan kedalam tanah

\section{Pembahasan}

Perempuan Kerinci adalah perempuan berprilaku baik yang menuruti perintah orangtua ataupun suami. Penerapan pola tingkahlaku Perempuan Kerinci harus sesuai dengan icopake. Icopake uhang Kincai batangkeng pahang (orang Kerinci sering membawa golok jika berpergian jauh atau merantau) begitu juga dengan perempuan Kerinci ketika melakukan perjalanan jauh ia selalu membawa pisau kecil yang dijadikannya sebagai tusuk kondenya, hal tersebut digunakan sebagai alat pertahanan jika terjadi sesuatu hal yang tidak diinginkan.

Penciptaan karya ini menggambarkan tentang kekaguman pengkarya terhadap perempuan Kerinci yang diwujudkan kedalam karya seni lukis dengan menghadirkan berbagai kegiatan yang dilakukan oleh perempuan Kerinci dalam kehidupan sehari-hari. Perwujudan karya menggunakan konsep reinterpretasi yang menggambarkan kembali aktivitas perempuan Kerinci terutama bertani, dengan menghadirkan 


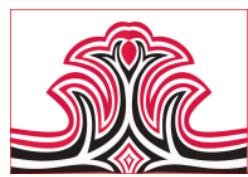

benda-benda zaman dahulu atau meminjam idiom tradisi untuk menciptakan karya seni modern seperti jangki, tapu, kuluk, baju kurung lihih, dan kebaya singkek. Hadirnya idiom tradisi tidak lagi sebagai penuangan ide secara tematik tetapi sebagai simbol tekstual yang disodorkan seniman untuk memberi kebebasan tafsir (Dharsono, 2016:113).

\section{KESIMPULAN DAN SARAN}

1.Kesimpulan

Penciptaan kaya ini terinspirasi dari perempuan kerinci, dalam pengamatan terhadap perempuan Kerinci. perempuan kerinci merupakan perempuan yang patuh terhadap kata junjungan seperti kata orang tua dan juga suami. Langkah awal dalam penciptaan karya ini yakni mencari sumber informasi tentang perempuan Kerinci melalui wawancara, buku, dan internet. Selanjutnya melalukan observasi terhadap aktivitas yang dilakukan oleh perempuan Kerinci yang merupakan tentang aktivitas bertani karena mayoritas masyarakat Kerinci sebagai petani jadi tidak salah kalau penciptaan kaya ini mengakat tentang aktivitas bertani.

Nilai dan makna yang terkandung dalam karya ini hendaknya memberikan dampak positif bagi kehidupan masyarakat Kerinci terutama perempuan Kerinci. secara global proses yang dilakukan dari awal menciptakan karya sampai akhir ada yang sesuai ada yang tidak sesuai dengan yang direncanakan. Hal tersebut bukan berarti gagal, tetapi banyaknya masukan dan kritikan yang diterima hal tersebut bisa saja terjadi untuk meningkatkan kualitas karya yang diciptakan.

\section{Saran}

Selama melakukan riset terhadap perempuan Kerinci masih banyak hal yang menarik ditemukan, seperti sistem matrilineal di Kerinci yang menjadikan perempuan sebagai seorang raja yang memiliki kedudukan tinggi atau sangat disegani yang disebut dengan bilan salih. Hal ini dapat menjadi referensi bagi pengkarya untuk melahirkan karya nantinya.

\section{DAFTAR RUJUKAN}

Risnal. M, dkk. 1996. Pakaian Adat Masyarakat

Kerinci. Jambi. Departemen Pendididkan dan Kebudayaan Museum Jambi.

Sony, Kartika. dkk. 2007. Kritik Seni.

Badung:Rekayasa Sains. . 2016. Kreasi Artistik.

Surakarta: Citra Sain
Gorga Jurnal Seni Rupa

Volume 07 Nomor 02 p-ISSN: 2301-5942 | e-ISSN: 2580-2380

dan Gerakan Seni Rupa. Universitas Michingan, Kansius. 